\title{
Influence of respiratory rate and end-expiratory pressure variation on cyclic alveolar recruitment in an experimental lung injury model
}

Erik K Hartmann ${ }^{1 *}$, Stefan Boehme², Alexander Bentley ${ }^{1}$, Bastian Duenges ${ }^{1}$, Klaus U Klein², Amelie Elsaesser ${ }^{3}$, James E Baumgardner ${ }^{4}$, Matthias David ${ }^{1}$ and Klaus Markstaller ${ }^{2}$

\begin{abstract}
Introduction: Cyclic alveolar recruitment/derecruitment (R/D) is an important mechanism of ventilator-associated lung injury. In experimental models this process can be measured with high temporal resolution by detection of respiratory-dependent oscillations of the $\mathrm{paO}_{2}\left(\Delta \mathrm{paO}_{2}\right)$. A previous study showed that end-expiratory collapse can be prevented by an increased respiratory rate in saline-lavaged rabbits. The current study compares the effects of increased positive end-expiratory pressure (PEEP) versus an individually titrated respiratory rate (RR ind) on intra-tidal amplitude of $\triangle \mathrm{paO}_{2}$ and on average $\mathrm{paO}_{2}$ in saline-lavaged pigs.
\end{abstract}

Methods: Acute lung injury was induced by bronchoalveolar lavage in 16 anaesthetized pigs. R/D was induced and measured by a fast-responding intra-aortic probe measuring $\mathrm{paO}_{2}$. Ventilatory interventions $\left(\mathrm{RR}_{\text {ind }}(\mathrm{n}=8)\right.$ versus extrinsic PEEP $(n=8)$ ) were applied for 30 minutes to reduce $\Delta \mathrm{paO}_{2}$. Haemodynamics, spirometry and $\Delta$ $\mathrm{paO}_{2}$ were monitored and the Ventilation/Perfusion distributions were assessed by multiple inert gas elimination. The main endpoints average and $\Delta \mathrm{paO}_{2}$ following the interventions were analysed by Mann-Whitney-U-Test and Bonferroni's correction. The secondary parameters were tested in an explorative manner.

Results: Both interventions reduced $\Delta \mathrm{paO}_{2}$. In the $\mathrm{RR}_{\text {ind }}$ group, $\Delta \mathrm{paO}_{2}$ was significantly smaller $(P<0.001)$. The average $\mathrm{paO}_{2}$ continuously decreased following $\mathrm{RR}_{\text {ind }}$ and was significantly higher in the PEEP group $(P<0.001)$. A sustained difference of the ventilation/perfusion distribution and shunt fractions confirms these findings. The $\mathrm{RR}_{\text {ind }}$ application required less vasopressor administration.

Conclusions: Different recruitment kinetics were found compared to previous small animal models and these differences were primarily determined by kinetics of end-expiratory collapse. In this porcine model, respiratory rate and increased PEEP were both effective in reducing the amplitude of $\mathrm{paO}_{2}$ oscillations. In contrast to a recent study in a small animal model, however, increased respiratory rate did not maintain end-expiratory recruitment and ultimately resulted in reduced average $\mathrm{paO}_{2}$ and increased shunt fraction.

Keywords: acute lung injury, cyclic alveolar recruitment, porcine model, respiratory- dependent paO 2 oscillations, varying shunt fractions

\section{Introduction}

Due to a wide variety of pulmonary and extrapulmonary aetiologies, acute lung injury (ALI) and the acute respiratory distress syndrome, as defined by the American European Consensus Conference in 1994 [1],

\footnotetext{
* Correspondence: hartmane@uni-mainz.de

'Department of Anaesthesiology, Medical Center of the Johannes

Gutenberg-University, Mainz 55131, Germany

Full list of author information is available at the end of the article
}

remain major challenges in modern critical care medicine. A mortality reduction was achieved within the past 10 to 15 years and accompanied by rapid progress in assessing and understanding the underlying mechanisms. Nevertheless, mortality rates of more than $30 \%$ are still described [2,3]. Mechanical ventilation is commonly regarded as the cornerstone strategy in ALI, although various other supportive therapies are known to have a beneficial effect $[4,5]$. However, 
the optimal ventilatory setting in ALI is still controversially discussed. Moreover, an additional injury to the pre-injured lung, defined as ventilator-associated lung injury (VALI), can result from mechanical ventilation. Systemic or pulmonary inflammation caused by mediators that are released within the lung through injurious ventilation (biotrauma) is the consequence. Lung protective ventilation strategies aiming to minimize baro- and volutrauma by limitation of inspiratory pressure and tidal volume led to improved survival outcome and are accepted as the current standard therapy $[6,7]$. In addition to volutrauma (stretch injury), atelectrauma (cyclic alveolar recruitment and derecruitment, R/D), is another major component of VALI. Within the injured lung, inspiratory pressure can lead to an opening of collapsed lung areas, which immediately re-collapse in expiration. This breath by breath collapse is associated with shear-stress and inflammation and, therefore, promotes the pre-existing injury of lung tissue [8]. Cyclic R/D has recently been the focus of research studies, particularly in terms of clinical detection and treatment $[9,10]$. Variations of the pulmonary shunt fraction caused by cyclic R/D that can induce respiratory-dependent oscillations of the arterial partial pressure of oxygen $\left(\mathrm{paO}_{2}\right)$ were described by Baumgardner et al. by means of ultrafast, invasive measurement of the $\mathrm{paO}_{2}$ [11]. The occurrence and amplitudes of $\mathrm{paO}_{2}$ oscillations $\left(\Delta \mathrm{paO}_{2}\right)$ can be used to quantify the extent of cyclic R/D [10]. Theoretically, positive end-expiratory pressure (PEEP) that exceeds the lower inflection point of the static pressure-volume-curve should effectively maintain end-expiratory recruitment, minimize cyclic R/D induced biotrauma and improve gas exchange. However, limitations due to over-distension of non-dependent lung areas leading to volutrauma or circulatory depression may override these benefits [12-14]. Furthermore, PEEP does not respond to the dynamic behaviour and the distinct time constants underlying R/D of atelectasis $[15,16]$. Other experimental strategies to maintain end-expiratory recruitment include, shortening expiration times or an increased respiratory rate (RR) [11,17].

We hypothesised that: (1) a goal-directed RR and increased PEEP can both reduce the amplitude of intratidal $\Delta \mathrm{paO}_{2}$ to less than $50 \mathrm{~mm} \mathrm{Hg}$; and (2) RR and PEEP adjusted to minimize intra-tidal $\Delta \mathrm{paO}_{2}$ result in equivalent average lung recruitment by avoiding endexpiratory collapse. Hence, this study aims to compare the effectiveness of high extrinsic PEEP and an individually titrated $R R\left(R R_{\text {ind }}\right)$ as ventilatory interventions in a porcine ALI model designed to create a maximum of cyclic R/D. Furthermore, effects on haemodynamics, oxygenation and ventilation/perfusion $(\dot{\mathrm{V}} / \dot{\mathrm{Q}})$ distribution are characterised.

\section{Materials and methods}

After approval by the State and Institutional Animal Care Committee (Landesuntersuchungsamt RheinlandPfalz, Koblenz, Germany; approval number: 23177-07/ G09-1-029), 16 juvenile pigs (German country race, weight 25 to $27 \mathrm{~kg}$ ) were investigated in a prospectiverandomised study. Two pilot experiments were conducted for set up and feasibility of the protocol.

\section{Anaesthesia and preparation}

Following sedation by an intramuscular injection of ketamine $\left(8 \mathrm{mg} \mathrm{kg}^{-1}\right)$ and midazolam $\left(0.2 \mathrm{mg} \mathrm{kg}^{-1}\right)$ and vascular access via an ear vein, anaesthesia was induced by intravenous (i.v.) administration of propofol (4 mg $\left.\mathrm{kg}^{-1}\right)$, fentanyl $\left(4 \mu \mathrm{g} \mathrm{kg}^{-1}\right)$ and a single dose of pancuronium $\left(0.15 \mathrm{mg} \mathrm{kg}^{-1}\right)$ to facilitate endotracheal intubation. Anaesthesia was maintained by a continuous i.v. infusion of propofol (8-12 $\left.\mathrm{mg} \mathrm{kg}^{-1} \mathrm{~h}^{-1}\right)$ and fentanyl (0.1 to $0.2 \mathrm{mg} \mathrm{h}^{-1}$ ) for the entire experiment. After orotracheal intubation using a standard (internal diameter 7.5 $\mathrm{mm}$ ) endotracheal tube, pressure-controlled ventilation (Ventilator: Servo 900C, Siemens, Erlangen, Germany) was initiated with a tidal volume of 10 to $12 \mathrm{mg} \mathrm{kg}^{-1}$, PEEP of 5 mbar, fraction of inspired oxygen $\left(\mathrm{FiO}_{2}\right)$ of 0.3 to 0.4 , inspiration to expiration ratio (I:E) of $1: 2$ and a variable $R R$ to maintain normocapnia. A balanced saline solution was infused continuously $\left(5 \mathrm{ml} \mathrm{kg}^{-1} \mathrm{~h}^{-1}\right)$.

The following vascular catheters were placed by surgical cut-down: an arterial line and a $\mathrm{PiCCO}^{\circledR}$ catheter (Pulsion Medical Systems, Munich, Germany) via the left and right femoral arteries, respectively; a central venous line via a femoral vein; an introducer for a pulmonary artery catheter (Edwards Lifescience, Irvine, CA, USA) via the right external jugular vein; an arterial introducer for ultrafast measurement of the $\mathrm{paO}_{2}$ via the right carotid artery. Spirometry and haemodynamic parameters were continuously recorded by a Datex S/5 unit (Datex Ohmeda GmbH, Duisburg, Germany). To ensure correct catheter positioning the typical pressure waveforms of the arterial, pulmonary arterial and central venous pressure were obtained and referenced to the mid-chest level. A Rapidlab 248 device (Bayer Healthcare, Leverkusen, Germany) was applied for arterial and mixed venous blood gas analyses. Body temperature was measured by a rectal probe and body surface warming was performed by a heating blanket system. Cardiac output (CO) was assessed by single-indicator transpulmonary thermodilution using the $\mathrm{PiCCO}^{\circledR}$ system. Three repetitive i.v. injections of $10 \mathrm{ml}$ cooled $\left(<8^{\circ} \mathrm{C}\right)$ balanced saline solution were given for each calibration. 


\section{Ultrafast $\mathrm{paO}_{2}$ measurement}

Through the right carotid introducer, a fiberoptic probe (FOXY-AL300; Ocean Optics, Dunedin, FL, USA) measuring $\mathrm{paO}_{2}$ based on oxygen-sensitive fluorescence quenching with a time resolution up to $10 \mathrm{~Hz}$, was inserted into the ascending aorta. The probe was calibrated in vitro according to a previously reported routine $[9,18]$. The validity of the calibration was confirmed in vivo by repetitive blood gas analyses. For ultrafast data visualisation and storage, a dedicated acquisition software was used (OOI Sensors; Ocean Optics, Dunedin, FL, USA).

\section{Multiple Inert Gas Elimination Technique (MIGET)}

The novel micropore membrane inlet mass spectrometry (MMIMS)-MIGET was used for assessment of the $\dot{\mathrm{V}} / \dot{\mathrm{Q}}$ distribution. An additional shunt calculation from blood gas samples was performed by a previously described and porcine-specific algorithm [19]. A normal saline solution containing the six inert gases, sulphur hexafluoride, krypton, desflurane, enflurane, diethyl ether and acetone, was prepared by a senior chemist (BD). Twenty minutes of i.v. application with an infusion rate of $6 \mathrm{ml} \mathrm{minute^{-1 }}$ was conducted for every measurement to ensure steady state conditions. Afterwards, simultaneous arterial and mixed venous blood (each 5 $\mathrm{ml}$ ) was drawn over several breath cycles in gas-tight glass syringes and injected into the MMIMS-MIGET system. Retention of the inert gases was calculated as the ratio of arterial to mixed venous partial pressure. The $\dot{V} / \dot{Q}$ distribution was determined according to Evans and Wagner [20]. By means of the MMIMSMIGET only the perfusion-based $\dot{\mathrm{V}} / \dot{\mathrm{Q}}$ as fractions of the $\mathrm{CO}$ were analysed. Hence, no dead space data are available. The following standard ranges were defined: shunt $(\dot{\mathrm{V}} / \dot{\mathrm{Q}}<0.005)$, low $\dot{\mathrm{V}} / \dot{\mathrm{Q}}(0.005<\dot{\mathrm{V}} / \dot{\mathrm{Q}}<0.1)$, normal $\dot{\mathrm{V}} / \dot{\mathrm{Q}}(0.1<\dot{\mathrm{V}} / \dot{\mathrm{Q}}<10)$, high $\dot{\mathrm{V}} / \dot{\mathrm{Q}}(10<\dot{\mathrm{V}} / \dot{\mathrm{Q}}$ $>100)$.

\section{Lung injury model and baseline measurements}

Baseline measurements were conducted in a healthy state and in ALI. The $\mathrm{FiO}_{2}$ was set and maintained at 1.0 before the baseline. ALI was induced via repetitive bronchoalveolar lavages: the endotracheal tube was clamped in inspiration, $30 \mathrm{ml} \mathrm{kg}-1$ of warmed balanced saline solution were instilled by gravity and afterwards immediately removed. Bronchoalveolar lavages were repeated to achieve a $\mathrm{paO}_{2} / \mathrm{FiO}_{2}$ ratio $\leq 300 \mathrm{mmHg}$ at a PEEP of 5 mbar for 30 minutes. A fluid optimisation routine of 50 to $100 \mathrm{ml}$ of hydroxyethyl starch was added, if the mean arterial pressure (MAP) persisted < $60 \mathrm{mmHg}$ after ALI induction.

\section{Experimental protocol}

Following baseline measurements in ALI the animals were randomised into two intervention groups: 1) increase of the PEEP to 10 to 15 mbar (PEEP group) and 2 ) individually titrated respiratory rate $\left(R_{\text {ind }}\right.$ group).

The respirator settings were set up to peak inspiratory pressure $\left(\mathrm{P}_{\text {peak }}\right) 40$ mbar, zero PEEP, RR 5 to 8 minutes $^{-1}$ and $\mathrm{I}: \mathrm{E}$ of 1:4 in pressure-controlled mode to provoke maximal cyclic R/D (time point R/D I). The inability to cause cyclic R/D with the dedicated ventilator settings was defined as obligate criterion for exclusion. $\Delta \mathrm{paO}_{2}$ values with a stable amplitude $\geq 50 \mathrm{mmHg}$ were accepted as the pathophysiological correlate of considerable R/D in order to clearly exceed the reported variations that occur in healthy, anaesthetized animals $[10,11,21]$. Thereafter, the randomised intervention (Figure 1) was initiated to terminate cyclic R/D under continuous ultrafast $\mathrm{paO}_{2}$ measurement. In the PEEP group, extrinsic PEEP was immediately raised up to at least 10 mbar. Further increases were allowed up to a maximum of $15 \mathrm{mbar}$ if $\Delta$ $\mathrm{paO}_{2}$ was $>20 \mathrm{mmHg}$ and if the MAP was $>60 \mathrm{mmHg}$. Intrinsic PEEP was also measured dynamically as the difference between total and extrinsic set PEEP in both groups (as automated by a S/5 unit, Datex Ohmeda GmbH, Duisburg, Germany). The RR was titrated individually until a $\Delta \mathrm{paO}_{2}<20 \mathrm{mmHg}$ under real-time conditions was achieved. The peak and end-inspiratory airway pressures $\left(\mathrm{P}_{\text {peak }}, \mathrm{P}_{\text {endinsp }}\right)$ were held constant to the preintervention value in both groups. If haemodynamic instability, defined by a MAP $<60 \mathrm{mmHg}$, occurred after initiation of the interventions, i.v. epinephrine was administered continuously. The $\Delta$ and average $\mathrm{paO}_{2}$ values were reassessed 10, 20 and 30 minutes following the intervention. Spirometry and haemodynamic data were stored. Thereafter, the initial ventilator settings were set again to restore cyclic R/D (time point R/D II) and evaluate the influence of both interventions on the amount of recruitable lung tissue. MIMMS-MIGET measurements were performed during baseline and after 30 minutes of intervention. After completing the protocol the animals were euthanized in general anaesthesia by lethal injection of propofol $(200 \mathrm{mg})$ and potassium chloride (40 mmol).

\section{Statistical methods}

For a description of the continuous variables' distribution, the median and interquartile range (IQR) are given. Additional descriptive data are reported as mean and standard deviation $( \pm S D)$. The intergroup difference of the main endpoints $\Delta$ and average $\mathrm{paO}_{2}$ following the respective intervention was analysed using the mean of the 


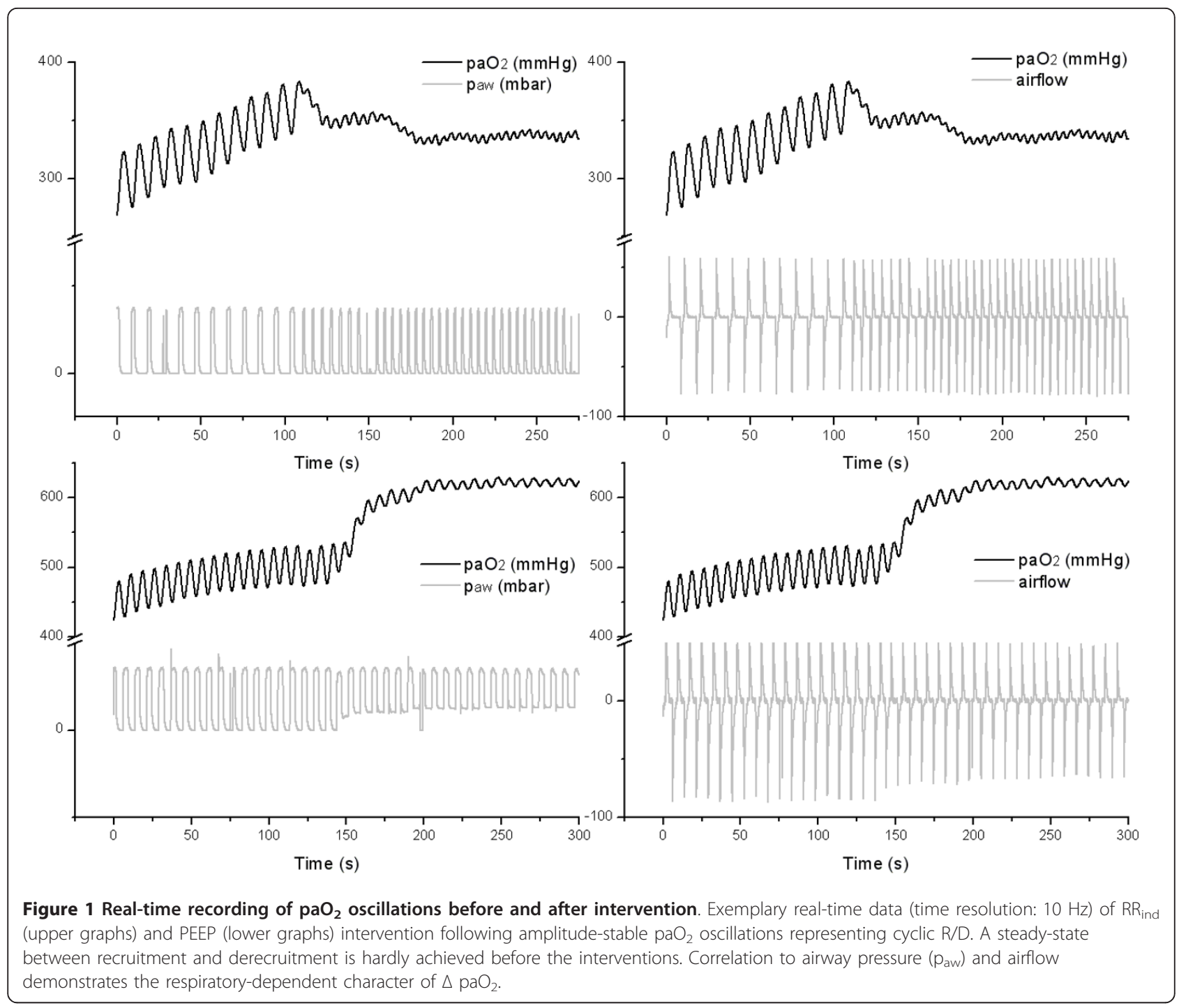

measurements over the different time points for every pig. These mean values were compared using Mann-WhitneyU-Tests. To account for multiple testing a simple Bonferroni correction was used for the two main endpoints. The multiple significance level was set at 5\%. Haemodynamic data and MMIMS-MIGET derived $\mathrm{V} / \dot{\mathrm{Q}}$ after 30 minutes were assessed as secondary endpoints in an explorative manner. The resulting $P$-values are descriptive only. All statistical analyses were performed using the statistical software $\mathrm{R}$ version 2.13.1.

\section{Results}

A total of 16 animals were included in the study. One animal died during ALI induction and was replaced by an additional animal. In the baseline measurements before provocation of $\mathrm{R} / \mathrm{D}$, acute lung injury $\left(\mathrm{paO}_{2} / \mathrm{FiO}_{2}\right.$ $<300 \mathrm{mmHg}$ ) was documented in both groups. The applied respirator settings and blood gas analyses are summarised in Table 1.

\section{Cyclic recruitment and oxygenation}

Cyclic R/D measured by respiratory-dependent oscillations of the $\mathrm{paO}_{2}$ was provoked in every animal. A median $\Delta \mathrm{paO}_{2}$ of $78(\mathrm{IQR}=22) \mathrm{mmHg}$ in the PEEP group and $72(I Q R=26) \mathrm{mmHg}$ in the $R R_{\text {ind }}$ group was observed. The corresponding median $\mathrm{paO}_{2}$ values were $288(\mathrm{IQR}=68) \mathrm{mmHg}$ (PEEP group) and $372(\mathrm{IQR}=$ 94) $\mathrm{mmHg}\left(\mathrm{RR}_{\text {ind }}\right.$ group). These differences were not statistically significant $\left(\Delta \mathrm{paO}_{2}: P=0.462 ; \mathrm{paO}_{2}: P=\right.$ 0.130). As a result of the defined protocol for adjusting $R R$ and PEEP, the $R R_{\text {ind }}$ intervention consisted of a titration to a RR of $15 \pm 1$ minute $^{-1}$, while in the PEEP group the PEEP increased up to $13 \pm 2$ mbar. In both groups an immediate reduction of the $\Delta \mathrm{paO}_{2}$ was achieved (Figure 2). The $\Delta \mathrm{paO}_{2}$ reduction was more 
Table 1 Ventilatory parameters and blood gas analyses (mean \pm SD)

\begin{tabular}{|c|c|c|c|c|c|c|c|c|c|c|}
\hline & $\begin{array}{l}\text { PEEP } \\
\text { group }\end{array}$ & & & & & $\begin{array}{l}\mathrm{RR}_{\text {ind }} \\
\text { group }\end{array}$ & & & & \\
\hline Parameters & $\begin{array}{l}\text { Baseline } \\
\text { ALI }\end{array}$ & R/D I & $\begin{array}{l}\text { Intervention } \\
\text { Initial }\end{array}$ & $\begin{array}{l}\text { Intervention } \\
10 \text { to } 30 \\
\text { minutes }\end{array}$ & R/D II & $\begin{array}{l}\text { Baseline } \\
\text { ALI }\end{array}$ & R/D I & $\begin{array}{l}\text { Intervention } \\
\text { Initial }\end{array}$ & $\begin{array}{l}\text { Intervention } \\
10 \text { to } 30 \\
\text { minutes }\end{array}$ & R/D II \\
\hline \multicolumn{11}{|l|}{ Ventilation } \\
\hline$P_{\text {peak }}$ (mbar) & $25 \pm 4$ & $40 \pm 4$ & $40 \pm 4$ & $40 \pm 4$ & $40 \pm 5$ & $20 \pm 3$ & $38 \pm 5$ & $37 \pm 3$ & $38 \pm 3$ & $45 \pm 7$ \\
\hline$P_{\text {endinsp }}$ (mbar) & $23 \pm 5$ & $35 \pm 4$ & $35 \pm 4$ & $35 \pm 4$ & $37 \pm 7$ & $19 \pm 3$ & $34 \pm 4$ & $33 \pm 3$ & $34 \pm 3$ & $40 \pm 9$ \\
\hline$P_{\text {mean }}($ mbar $)$ & $11 \pm 1$ & $14 \pm 3$ & $21 \pm 3$ & $22 \pm 3$ & $14 \pm 3$ & $10 \pm 1$ & $13 \pm 3$ & $13 \pm 3$ & $13 \pm 3$ & $15 \pm 4$ \\
\hline $\mathrm{RR}\left(\mathrm{min}^{-1}\right)$ & $28 \pm 5$ & $6 \pm 1$ & $6 \pm 1$ & $6 \pm 1$ & $6 \pm 1$ & $27 \pm 3$ & $6 \pm 1$ & $15 \pm 2$ & $17 \pm 3$ & $6 \pm 1$ \\
\hline PEEP $P_{\text {total }}(\mathrm{mbar})$ & $5 \pm 1$ & 0 & $13 \pm 1$ & $13 \pm 2$ & $\begin{array}{l}0.3 \pm \\
0.2\end{array}$ & $5 \pm 1$ & 0 & $0.1 \pm 0.1$ & $0.1 \pm 0.2$ & 0 \\
\hline$V_{t}\left(m / k^{-1}\right)$ & $10 \pm 1$ & $35 \pm 8$ & $24 \pm 5$ & $24 \pm 6$ & $41 \pm 9$ & $10 \pm 1$ & $36 \pm 7$ & $32 \pm 7$ & $28 \pm 6$ & $40 \pm 10$ \\
\hline $\mathrm{FiO}_{2}$ & 1.0 & 1.0 & 1.0 & 1.0 & 1.0 & 1.0 & 1.0 & 1.0 & 1.0 & 1.0 \\
\hline $\mathrm{T}_{\text {insp }}(\mathrm{s})$ & $0.7 \pm 0.2$ & $\begin{array}{l}2.0 \pm \\
0.4\end{array}$ & $2.0 \pm 0.4$ & $1.9 \pm 0.3$ & $\begin{array}{l}2.0 \pm \\
0.3\end{array}$ & $0.8 \pm 0.1$ & $\begin{array}{l}2.0 \pm \\
0.3\end{array}$ & $0.9 \pm 0.1$ & $0.8 \pm 0.1$ & $\begin{array}{l}2.1 \pm \\
0.4\end{array}$ \\
\hline$T_{\exp }(s)$ & $1.5 \pm 0.3$ & $\begin{array}{c}8.1 \pm \\
1.8\end{array}$ & $7.9 \pm 1.7$ & $7.6 \pm 1.2$ & $\begin{array}{l}8.2 \pm \\
1.3\end{array}$ & $1.5 \pm 0.3$ & $\begin{array}{l}7.9 \pm \\
1.1\end{array}$ & $3.4 \pm 0.3$ & $3.0 \pm 0.5$ & $\begin{array}{c}8.3 \pm \\
1.4\end{array}$ \\
\hline \multicolumn{11}{|l|}{$\begin{array}{l}\text { Blood gas } \\
\text { analysis }\end{array}$} \\
\hline ph & $7.3 \pm 0.1$ & & & $7.3 \pm 0.1$ & & $7.4 \pm 0.1$ & & & $7.5 \pm 0.1$ & \\
\hline $\mathrm{paO}_{2}(\mathrm{mmHg})$ & $199 \pm 69$ & & & $539 \pm 72$ & & $219 \pm 85$ & & & $163 \pm 71$ & \\
\hline $\begin{array}{l}\mathrm{paO}_{2}-\mathrm{Foxy} \\
(\mathrm{mmHg})\end{array}$ & $187 \pm 48$ & $\begin{array}{c}307 \pm \\
90\end{array}$ & $500 \pm 86$ & $550 \pm 96$ & $\begin{array}{c}353 \pm \\
131\end{array}$ & $223 \pm 58$ & $\begin{array}{c}372 \pm \\
111\end{array}$ & $381 \pm 131$ & $174 \pm 62$ & $\begin{array}{c}209 \pm \\
139\end{array}$ \\
\hline $\mathrm{paCO}_{2}(\mathrm{mmHg})$ & $62 \pm 12$ & & & $57 \pm 9$ & & $55 \pm 3$ & & & $32 \pm 7$ & \\
\hline $\mathrm{Hb}\left(\mathrm{mg} \mathrm{dl}{ }^{-1}\right)$ & $8 \pm 1$ & & & $9 \pm 1$ & & $9 \pm 2$ & & & $9 \pm 2$ & \\
\hline $\mathrm{BE}\left(\mathrm{mmol} \mathrm{l}^{-1}\right)$ & $2 \pm 4$ & & & $2 \pm 3$ & & $3 \pm 6$ & & & $4 \pm 4$ & \\
\hline $\mathrm{Q}_{s} / \mathrm{Q}_{\mathrm{t}}(\%)$ & $26 \pm 6$ & & & $6 \pm 5$ & & $24 \pm 5$ & & & $25 \pm 6$ & \\
\hline
\end{tabular}

$\mathrm{P}_{\text {mean }}$, mean airway pressure; $\mathrm{PEEP}_{\text {total }}, \mathrm{PEEP}_{\text {extrinsic }}+\mathrm{PEEP}$ intrinsic; $\mathrm{T}_{\text {insp }}$, inspiration time; $\mathrm{T}_{\text {exp }}$, expiration time; $\mathrm{paO}_{2}-\mathrm{Foxy}_{\text {, }}$ paO $\mathrm{O}_{2}$ measured by the ultrafast invasive probe. (Foxy-AL 300); $Q_{s} / Q_{t}(\%)$, calculated pulmonary shunt fraction. No blood gases were sampled during presence of high respiratory-dependent oscillations of the $\mathrm{paO}_{2}$ due to high fluctuations.

pronounced in the $\mathrm{RR}_{\text {ind }}$ group while in the PEEP group a higher $\Delta \mathrm{paO}_{2}$ persisted over 30 minutes $\left(P_{\text {adjusted }}<\right.$ 0.001 after Bonferroni correction). The application of high PEEP induced an increase in the average $\mathrm{paO}_{2}$. In the $\mathrm{RR}_{\text {ind }}$ group the reduction of $\Delta \mathrm{paO}_{2}$ was in contrast accompanied by a large decrease in average $\mathrm{paO}_{2}$ over 30 minutes (Figure 3; $P_{\text {adjusted }}<0.001$ after Bonferroni correction). At the end of every experiment the original settings to provoke R/D were repeated to restore $R / D$ (R/D II). In the PEEP group the readjustment to the initial respiratory setting (Table 1 ) induced a higher $\Delta$ $\mathrm{paO}_{2}(101(\mathrm{IQR}=59) \mathrm{mmHg})$ than recorded before the PEEP increase. In the $\mathrm{RR}_{\text {ind }}$ group the $\Delta \mathrm{paO}_{2}$ was 58 $(\mathrm{IQR}=53) \mathrm{mmHg}$, while in four animals the $\Delta \mathrm{paO}_{2}$ was $<50 \mathrm{mmHg}$ despite a $\mathrm{P}_{\text {peak }}$ increase up to $45 \pm 7$ mbar. Hence, the PEEP intervention led a higher amount of recruitable lung tissue, while the $R R_{\text {ind }}$ induced an increase of non-recruitable, fixed atelectasis.

\section{Analysis of the ventilation/perfusion distribution}

The perfusion-based $\dot{\mathrm{V}} / \dot{\mathrm{Q}}$ analysis showed healthy conditions (normal $\dot{\mathrm{V}} / \dot{\mathrm{Q}}: 96 \pm 5 \%$ in the PEEP group; $90 \pm$
$14 \%$ in the $\mathrm{RR}_{\text {ind }}$ group). A sustained impairment occurred following ALI induction before induction of $\Delta$ $\mathrm{paO}_{2}$ in both groups (normal $\dot{\mathrm{V}} / \dot{\mathrm{Q}}: 65 \pm 11 \%$ versus 74 $\pm 14 \%$ ). After 30 minutes of intervention (Figure 4 ) the PEEP application led to pulmonary recruitment corresponding to the reported $\mathrm{paO}_{2}$ values: shunt fraction of $3 \%(\mathrm{IQR}=4)$, low $\dot{\mathrm{V}} / \dot{\mathrm{Q}} 0 \%(\mathrm{IQR}=0.2)$, normal $\dot{\mathrm{V}} / \dot{\mathrm{Q}}$ $96 \%(\mathrm{IQR}=4)$ and high $\mathrm{V} / \dot{\mathrm{Q}} 1 \%(\mathrm{IQR}=1)$. Compared to the $\mathrm{RR}_{\text {ind }}$ group (shunt $15 \%(\mathrm{IQR}=6)$, low $\dot{\mathrm{V}} / \dot{\mathrm{Q}}$ $24 \%(\mathrm{IQR}=9)$, normal $\dot{\mathrm{V}} / \dot{\mathrm{Q}} 52 \%(\mathrm{IQR}=15)$, high $\dot{\mathrm{V}} / \dot{\mathrm{Q}} 3 \%(\mathrm{IQR}=6)$ ), a considerably improved overall lung function defined by the MMIMS-MIGET was witnessed. Venous admixture was calculated from blood gas data at baseline and after initiation of the respective interventions, but not during presence of high $\Delta \mathrm{paO}_{2}$, due to high fluctuations of the blood gases (Table 1).

\section{Haemodynamics}

The haemodynamic parameters are summarised in Table 2. To maintain stable testing conditions despite 


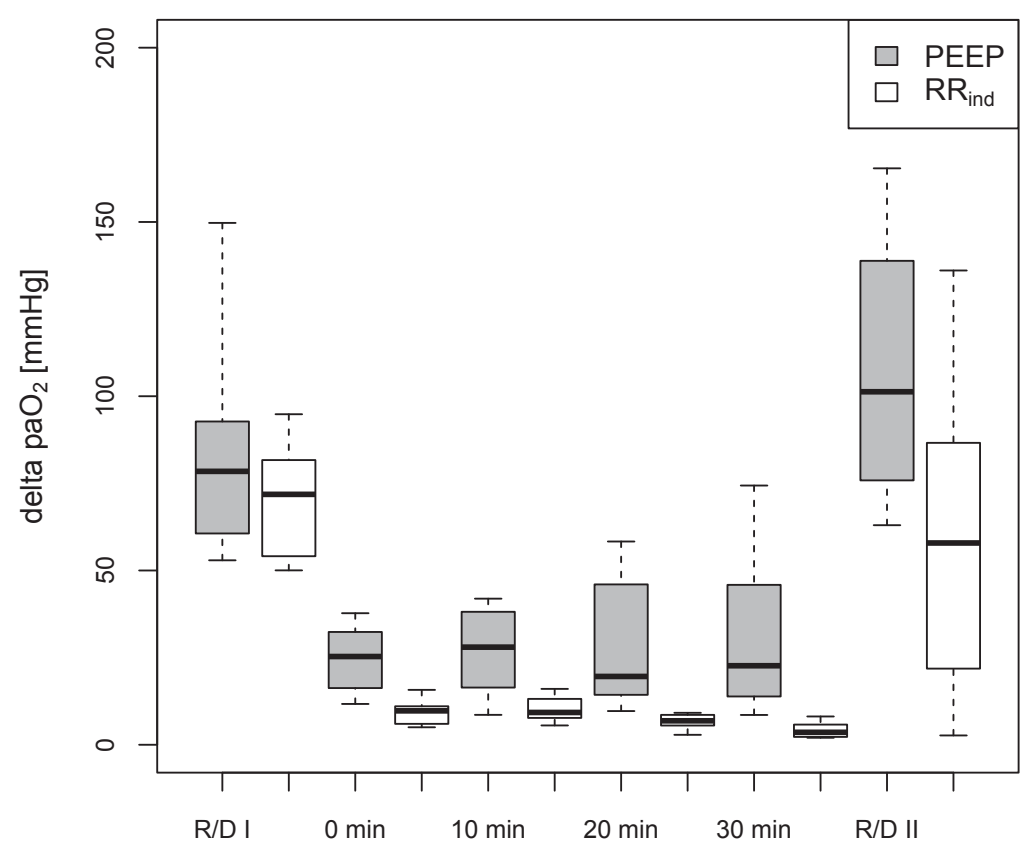

Figure 2 Time chart of the $\Delta \mathbf{p a O}_{2} . \Delta \mathrm{paO}_{2}(\mathrm{mmHg})$ after induction (R/D I), within 30 minutes of intervention and after re-induction (R/D II): no respiratory-dependent $\Delta \mathrm{paO}_{2}$ was founded before provocation. A significantly higher $\Delta \mathrm{paO}_{2}$ persists following PEEP intervention ( $\mathrm{p}_{\text {adjusted }}<0.001$ after Bonferroni correction). In four animals of the $\mathrm{RR}_{\text {ind }}$ group no $\Delta \mathrm{paO}_{2}$ with an amplitude $\geq 50 \mathrm{mmHg}$ was inducible in R/D II due to fixed atelectasis.

the challenging ventilator setting in this R/D model, a decrease of the MAP $<60 \mathrm{~mm} \mathrm{Hg}$ was treated by continuous i.v. administration of epinephrine. The vasopressor requirement to achieve the defined criterion was higher in the PEEP group $(P<0.05)$. No intergroup differences in MAP and CO (each $P>0.05$ ) were detected over 30 minutes. The mixed venous oxygen saturation $\left(\mathrm{SvO}_{2}\right)$ decreased over time in the $\mathrm{RR}_{\text {ind }}$ when compared to the PEEP group $(P<0.05)$.



Figure 3 Time chart of the average $\mathrm{paO}_{2}$. Average $\mathrm{paO}_{2}(\mathrm{mmHg})$ after induction $(\mathrm{R} / \mathrm{D} \mathrm{I})$, within 30 minutes of intervention and after reinduction (R/D II): a significantly decreased oxygenation develops following $R R_{\text {ind }}$ intervention while PEEP induces a stable lung recruitment ( adjusted $_{\text {a }} 0.001$ after Bonferroni correction). 


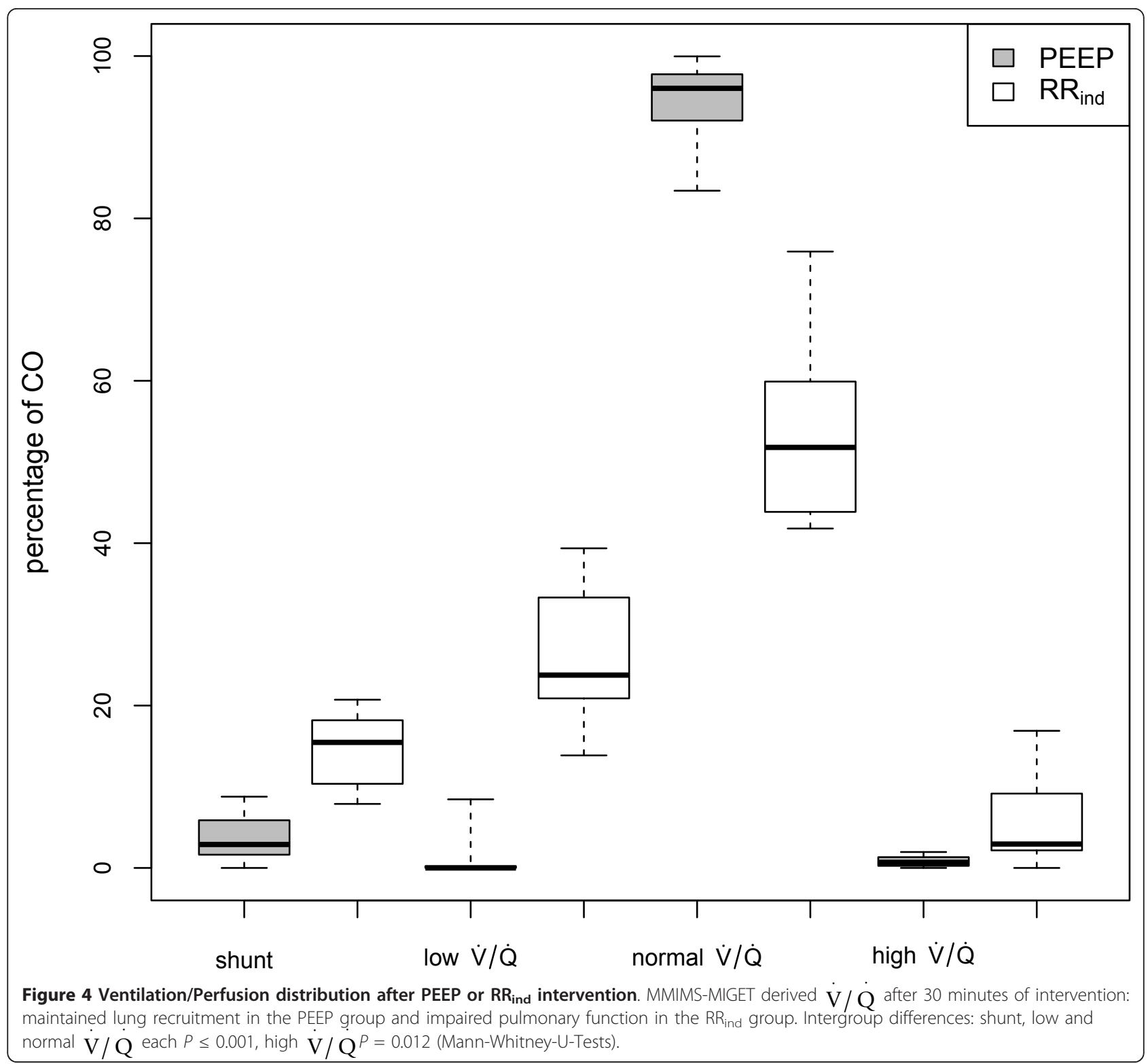

Table 2 Haemodynamic data and vasopressor support (median (IQR))

\begin{tabular}{|c|c|c|c|c|c|c|c|c|c|c|}
\hline & $\begin{array}{l}\text { PEEP } \\
\text { group }\end{array}$ & & & & & $\begin{array}{l}\mathrm{RR}_{\text {ind }} \\
\text { group }\end{array}$ & & & & \\
\hline Parameter & $\begin{array}{l}\text { Baseline } \\
\text { ALI }\end{array}$ & R/D I & $\begin{array}{l}\text { Intervention } \\
\text { Initial }\end{array}$ & $\begin{array}{l}\text { Intervention } \\
10 \text { to } 30 \\
\text { minutes }\end{array}$ & R/D II & $\begin{array}{l}\text { Baseline } \\
\text { ALI }\end{array}$ & R/D I & $\begin{array}{l}\text { Intervention } \\
\text { Initial }\end{array}$ & $\begin{array}{c}\text { Intervention } \\
10 \text { to } 30 \\
\text { minutes }\end{array}$ & $\begin{array}{c}\mathrm{R} / \mathrm{D} \\
\mathrm{II}\end{array}$ \\
\hline MAP (mmHg) & $91(29)$ & $\begin{array}{l}73 \\
(18)\end{array}$ & $61(24)$ & $66(4)$ & $\begin{array}{c}74(12) \\
*\end{array}$ & 99 (26) & $\begin{array}{c}84 \\
(24)\end{array}$ & 78 (34) & $74(24)$ & $\begin{array}{c}61 \\
(4)^{*}\end{array}$ \\
\hline $\mathrm{CO}\left(\mid \mathrm{min}^{-1}\right)$ & $3.7(1.1)$ & $\begin{array}{c}3.7 \\
(1.1)\end{array}$ & & $2.9(0.6)$ & & $3.3(0.7)$ & $\begin{array}{c}3.5 \\
(0.8)\end{array}$ & & $3.1(1.0)$ & \\
\hline $\mathrm{SvO}_{2}(\%)$ & $83(14)$ & & & $78(8)^{*}$ & & $81(8)$ & & & $66(12)^{*}$ & \\
\hline $\begin{array}{c}\text { Epinephrine }\left(\mu \mathrm{g} \mathrm{kg}{ }^{-1}\right. \\
\left.\min ^{-1}\right)\end{array}$ & 0 & 0 & $0.2(0.1)^{*}$ & $0.2(0.1)^{*}$ & $\begin{array}{c}0.2 \\
(0.1)^{*}\end{array}$ & 0 & 0 & $0(0.1)^{*}$ & $0(0.02)^{*}$ & $0^{*}$ \\
\hline
\end{tabular}

\footnotetext{
* indicate intergroup difference $(P<0.05$, Mann-Whitney-U-Test).
} 


\section{Discussion}

The present study compares the effect of an individually titrated RR versus high extrinsic PEEP on respiratorydependent oscillations of the $\mathrm{paO}_{2}$ in a porcine model of cyclic R/D.

\section{Occurrence of $\Delta \mathrm{paO}_{2}$ in experimental models}

Small amplitudes of $\Delta \mathrm{paO}_{2}$ ranging from 8.9 to 20 $\mathrm{mmHg}$ have been reported in different anaesthetised and mechanically ventilated animal species in a healthy state $[10,11,21]$. The overall average of $\Delta \mathrm{paO}_{2}$ amplitude $(77 \pm 25 \mathrm{mmHg}, \mathrm{n}=16)$ during the initial period of maximal cyclical recruitment (R/D I) is well above this range. In lung lavaged rabbits $\Delta \mathrm{paO}_{2}$ values of 390 $\pm 39 \mathrm{mmHg}$ and $283 \pm 128 \mathrm{~mm} \mathrm{Hg}$ were described by Baumgardner et al. [11] and Pfeiffer et al. [22]. Much lower amplitudes of $\Delta \mathrm{paO}_{2}$ (estimated at up to 69 $\mathrm{mmHg}$ ) were reported in a canine lavage model [23]. Few exemplary data of cyclic R/D measured by $\Delta \mathrm{paO}_{2}$ in porcine models are available [9]. In our model, prolonged exhalation times $(8.0 \pm 1.4 \mathrm{~s}, \mathrm{n}=16)$ produced the largest $\Delta \mathrm{paO}_{2}$, while in rabbits a $2: 1$ inverse ratio ventilation (average exhalation time $2.9 \mathrm{~s}$ ) induced the highest $\Delta \mathrm{paO}_{2}$ [17]. The occurrence of maximum $\Delta$ $\mathrm{paO}_{2}$ when exhalation time is longer than inhalation time suggests that, in contrast to rabbit models, derecruitment during exhalation is slower than recruitment during inhalation. Our data suggest that in lavaged pig lungs, minor amounts of $\Delta \mathrm{paO}_{2}$ occur even at low RR and larger inspiratory and expiratory time intervals are required to induce $R / D$ in large animals.

\section{Influence of RR and PEEP on $\Delta \mathrm{paO}_{2}$}

After the demonstration by dynamic computed tomography that collapse of lung tissue is a time-dependent process $[15,16]$, the impact of an increased respiratory rate and associated diminished exhalation time on cyclic R/D was investigated in rabbit models [11,17]. Increased respiratory rate in lavaged rabbits reduced cyclic R/D and maintained end-expiratory recruitment, an effect that was not mediated by intrinsic PEEP. The $R R_{\text {ind }}$ induced reduction of $\Delta \mathrm{paO}_{2}$ similarly was not related to a relevant intrinsic PEEP in our study (Table 1). The current study featured a titration of the RR under real-time monitoring of $\mathrm{R} / \mathrm{D}$ to achieve the targeted $\Delta \mathrm{paO}_{2}$ and was compared to the maximum PEEP that did not compromise haemodynamic stability. Furthermore, the interventional settings (high PEEP, $\mathrm{RR}_{\text {ind }}$ ) were maintained for a longer period of 30 minutes. Both interventions immediately induced a decrease of $\Delta \mathrm{paO}_{2}$. In the short run, $R R_{\text {ind }}$ more effectively reduced respiratory-dependent oscillations of the $\mathrm{paO}_{2}$, while in the PEEP group a measurable $\Delta \mathrm{paO}_{2}$ persisted over 30 minutes (Figure 2).
In contrast to a prior study [17] and despite the favourable effect on $\Delta \mathrm{paO}_{2}$, the $\mathrm{RR}_{\text {ind }}$ intervention clearly failed to maintain or increase oxygenation like the PEEP application. These findings are reflected in sustained impairment of the $\dot{V} / \dot{Q}$ in the $R R_{\text {ind }}$ group. The MMIMS-MIGET showed a persistent average shunt fraction in both groups (Figure 4), which was consistent with the conventional shunt calculation (Table 1). Neither MMIMS-MIGET shunt nor conventional calculation, however, offers a dynamic assessment of the pulmonary shunt that is capable of following fast, respiratory-dependent variations. The persistence and intergroup differences of $\Delta \mathrm{paO}_{2}$ are, therefore, not directly related to the average shunt values. The significantly lower amount of atelectasis in the PEEP group (shunt fraction: $3 \%(\mathrm{IQR}=4)$ ) is still exposed to high peak pressures and long exhalation times and may, therefore, be recruited cyclically. In the high range of $\mathrm{paO}_{2}$, even very small changes in shunt fraction around a mean value of $3 \%$ are capable of producing substantial $\Delta \mathrm{paO}_{2}$ (online supplement of [11]). The persisting $\Delta$ $\mathrm{paO}_{2}$ of $23(\mathrm{IQR}=26) \mathrm{mmHg}$ in the PEEP group is, therefore, not inconsistent with the small average shunt of about $3 \%$. In contrast, following the $\mathrm{RR}_{\text {ind }}$ intervention the average $\mathrm{paO}_{2}$ is much lower and the average shunt fraction is much larger, but the small oscillations of $\mathrm{paO}_{2}$ suggest that very little of the atelectatic lung is recruited cyclically. Therefore, there appears to be less cyclic $R / D$ in the $R R_{\text {ind }}$ group, compared to the PEEP group.

The optimal level of PEEP in ALI is still controversial and presumably depends on the extent and severity of the underlying injury [13]. Referring to the "baby lung" concept, a forced reopening of all collapsed lung areas may lead to further injury and hyperinflation of the lung parenchyma $[24,25]$. Optimal parameters to titrate the $\mathrm{RR}$ remain unclear since the guidance by $\Delta \mathrm{paO}_{2}$ alone was effective only in diminution of $\Delta \mathrm{paO}_{2}$, but resulted in a markedly decreased average $\mathrm{paO}_{2}$ and lung recruitment. Although the $R_{\text {ind }}$ approach reduces the exhalation time per breath cycle, our results suggest that in this model $\mathrm{R} / \mathrm{D}$ is limited through $\mathrm{RR}_{\text {ind }}$, not by preventing end-expiratory collapse, but rather by limiting inspiratory recruitment. The RR may play a role as an intervention for cyclic R/D only if gas exchange is maintained by an adequate PEEP.

The slow approach to a steady state average $\mathrm{paO}_{2}$ after $R_{\text {ind }}$ (over 30 minutes in Figure 3) also supports the assumption that R/D in saline-lavaged pigs is a fairly slow process. Cyclic R/D may not have been completed within a single inspiration or exhalation in this experiment. The initial provocation of cyclic R/D offers comparable findings (Figure 1) in that immediately after R/D 
induction there was often a pronounced slow drift in the average $\mathrm{paO}_{2}$.

\section{Influence of RR and PEEP on haemodynamics}

Especially in a state of compromised haemodynamics, respiratory interventions should avoid negative haemodynamic effects. Syring et al. [17] noted a greater $\mathrm{CO}$ and $\mathrm{SvO}_{2}$ when the RR was used to prevent end-expiratory collapse. Consistent with this concept the animals in the $\mathrm{RR}_{\text {ind }}$ group required less vasopressor administration $(P<0.05)$. The haemodynamic alterations were regarded as only secondary in the present study. The primary focus was set on maintaining stable conditions for the assessment of respiratory-dependent $\mathrm{paO}_{2}$ variations. It should be noted that the protocol for vasopressor support was based on MAP. The decreases in MAP in the high PEEP group could be associated with left ventricular afterload reduction rather than compromised CO. The $\mathrm{SvO}_{2}$ declined over 30 minutes in the $\mathrm{RR}_{\text {ind }}$ setting despite comparable MAP and CO. However, this may be related to the impaired pulmonary gas exchange and oxygenation rather than an effect of reduced CO.

\section{Detection of R/D}

Cyclic R/D is not detectable by currently available routine clinical monitoring. Dynamic computed tomography, the current gold standard, offers the highest temporal and spatial resolution to monitor dynamic processes like R/D [26]. However, radiation exposure and the need for patient transport limit the practicability in the critically ill. The indirect method focussing on $\Delta$ $\mathrm{paO}_{2}$ and varying shunt fractions by an indwelling, invasive probe is an experimental technology. The concept of detecting R/D indirectly by $\Delta \mathrm{paO}_{2}$ may lead to translation to the clinics as related approaches might be developed in the near future $[9,27,28]$.

\section{Limitations of the study}

The lavage model imitates certain features of clinical ALI, particularly surfactant dysfunction and depletion, but, of course, is not identical with ALI. It is widely used to examine the extent and characteristics of atelectasis and alveolar recruitment [29]. Additionally, our experimental model was designed to produce a mild degree of injury with a small amount of fixed shunt and a large amount of recruitable atelectasis. More severe degrees of injury will require further studies. Finally, our observations were collected over a relatively short period of time, compared to the clinical course of ALI. Although some experimental studies indicated a more severe damage and higher inflammatory response in recruiting and derecruiting lung areas [30,31], the long-term extent and impact on human ALI is yet to be determined.
Two experimental technologies were applied in the present study. The MMIMS is a novel and alternate method of MIGET [32,33]. Only the detection of the inert gases by mass spectrometry differs from the conventional gas chromatographic method. The MMIMS technology is still being evaluated in on-going studies. In a prior study, the MMIMS-MIGET derived shunt fraction was shown to be highly correlated to the conventionally calculated shunt [19]. The ultrafast $\mathrm{paO}_{2}$ measurement was previously applied and described in detail by several experimental studies $[11,17,18,22,30,34]$. But a rapidly responding $\mathrm{paO}_{2}$ probe is not yet available for clinical use. One limitation, in the clinical setting, for the use of $\Delta \mathrm{paO}_{2}$ as an index of varying shunt fraction is that the oscillation amplitude is blunted at low haemoglobin saturations. Beyond a $\mathrm{paO}_{2}$ of $90 \mathrm{mmHg}$ a complete saturation of the haemoglobin is maintained [35], which allows for direct comparison of average and $\Delta \mathrm{paO}_{2}$ values.

The peak inspiratory pressure was held on a constant, high level during interventions in both groups, since the influence of the inspiratory pressure on alveolar recruitment is well known [36-38]. Due to the standardisation of the peak pressure following the intervention, however, the tidal volume differed between the two groups, while in the PEEP group also the mean airway pressure increased (Table 1).

\section{Conclusions}

The effects of extrinsic PEEP and a titrated RR on varying shunt fractions through cyclic R/D were characterised in a porcine lavage model. Different kinetics of alveolar recruitment were seen compared to previous small animal models.

Respiratory-dependent oscillations of the $\mathrm{paO}_{2}$ were reduced to a higher degree by high respiratory rates than by the feasible PEEP in the present model. The RR titration, however, resulted in a significantly lower average oxygenation and lung recruitment, compared to the use of high PEEP.

\section{Key messages}

- Cyclic alveolar recruitment measured by respiratory-dependent oscillations of the $\mathrm{paO}_{2}$ regularly occurs in saline-lavaged pigs during non-protective ventilation.

- As single interventions, increased RR and PEEP both significantly reduce respiratory-dependent oscillations of the $\mathrm{paO}_{2}$.

- PEEP maintains end-expiratory recruitment despite persisting amounts of cyclic recruitment, while RR as a single intervention does not maintain sufficient oxygenation and lung recruitment. 
- Maximal cyclic R/D in this large animal model is induced by prolonged exhalation times, in contrast to the maximal cyclic R/D by prolonged inspiration reported in a small animal model.

\section{Abbreviations}

ALI: acute lung injury; BE: base excess ( $\left.\mathrm{mmol} \mathrm{I}^{-1}\right)$; CO: cardiac output $\left(\mathrm{min}^{-1}\right)$; $\mathrm{FiO}_{2}$ : fraction of inspired oxygen; $\mathrm{Hb}$ : haemoglobin $\left(\mathrm{mg} \mathrm{dl}^{-1}\right)$ l:E: Inspiration to Expiration ratio; IQR: interquartile range; i.v: intravenous; MAP: mean arterial pressure $(\mathrm{mmHg})$; MMIMS-MIGET: micropore membrane inlet mass spectrometry - multiple inert gas elimination technique; $\mathrm{paO}_{2}$ : arterial partial pressure of oxygen $(\mathrm{mmHg})$; $\mathrm{paO}_{2}-\mathrm{Foxy}: \mathrm{paO}_{2}$ measured by the FOXY AL300 probe $(\mathrm{mmHg}) ; \triangle \mathrm{paO}_{2}$ : respiratory-dependent oscillations of $\mathrm{paO}_{2} ;$ PEEP: positive end-expiratory pressure (mbar); $P_{\text {endinsp: }}$ end-inspiratory pressure (mbar); $P_{\text {mean }}$ : mean airway pressure (mbar) $P_{\text {peak: }}$ peak inspiratory pressure (mbar); $Q_{s} / Q_{t}$ : calculated pulmonary shunt fraction (\%); R/D: cyclic alveolar recruitment and derecruitment; RR: respiratory rate $\left(\mathrm{min}^{-1}\right)$; RR ind: individually titrated RR ( $\left.\min ^{1}\right)$; SD: standard deviation; $\mathrm{SvO}_{2}$ : mixed venous oxygen saturation; $\mathrm{T}_{\text {inss: }}$ : inspiration time; $\mathrm{T}_{\text {exp: }}$ : expiration time; $\mathrm{V} \cdot / \mathrm{Q} \bullet$ ventilation/ perfusion distribution; VALI: ventilator-associated lung injury.
\end{abstract}

\section{Acknowledgements}

The study was funded by the German Research Council (DFG Pak 415: Ma 2398/6). All experiments were conducted at the Department of Anaesthesiology, Medical Center of the Johannes Gutenberg-University, Mainz, Germany. The authors want to thank Mrs. Dagmar Dirvonskis for support in logistics and laboratory organisation.

\section{Author details}

'Department of Anaesthesiology, Medical Center of the Johannes Gutenberg-University, Mainz 55131, Germany. ${ }^{2}$ Department of Anaesthesia, General Critical Care Medicine and Pain Therapy, Medical University of Vienna, Waehringer Guertel 18-20, A-1090 Vienna, Austria. ${ }^{3}$ Institute of Medical Biometry, Epidemiology and Informatics (IMBEI), Medical Center of the Johannes Gutenberg-University Mainz, 55131, Germany. ${ }^{4}$ Oscillogy LLC, 131 Milmont Ave, Folsom, Philadelphia, PA, 19033-3514, USA.

\section{Authors' contributions}

EKH coordinated and supervised the experiments. EKH, SB, AB, BD and KUK carried out the experiments. EKH, BD and SB performed the data analysis. $A E$ conducted the statistical analysis. EKH drafted the manuscript. KM, MD and $J E B$, participated in the study design, supervision of the laboratory and revision of the manuscript. All authors edited and approved the final manuscript.

\section{Competing interests}

JEB is the owner of Oscillogy LLC, which commercially distributes the MMIMS-MIGET system. JEB participated in set up and design of this study, but had no influence on data acquisition and analysis. None of the other authors declares a conflict of interest.

Received: 4 October 2011 Revised: 4 December 2011

Accepted: 16 January 2012 Published: 16 January 2012

\section{References}

1. Bernard GR, Artigas A, Brigham KL, Carlet J, Falke K, Hudson L, Lamy M, Legall JR, Morris A, Spragg R: The American-European Consensus Conference on ARDS. Definitions, mechanisms, relevant outcomes, and clinical trial coordination. Am J Respir Crit Care Med 1994, 149:818-824.

2. Phua J, Badia JR, Adhikari NK, Friedrich JO, Fowler RA, Singh JM, Scales DC, Stather DR, Li A, Jones A, Gattas DJ, Hallett D, Tomlinson G, Stewart TE, Ferguson ND: Has mortality from acute respiratory distress syndrome decreased over time?: A systematic review. Am J Respir Crit Care Med 2009, 179:220-227.

3. Zambon M, Vincent JL: Mortality rates for patients with acute lung injury/ ARDS have decreased over time. Chest 2008, 133:1120-1127.

4. Esan A, Hess DR, Raoof S, George L, Sessler CN: Severe hypoxemic respiratory failure: part 1-ventilatory strategies. Chest 2010, 137:1203-1216.
5. Raoof S, Goulet K, Esan A, Hess DR, Sessler CN: Severe hypoxemic respiratory failure: part 2-nonventilatory strategies. Chest 2010, 137:1437-1448.

6. Ventilation with lower tidal volumes as compared with traditional tidal volumes for acute lung injury and the acute respiratory distress syndrome. The Acute Respiratory Distress Syndrome Network. N Engl J Med 2000, 342:1301-1308.

7. Wheeler AP, Bernard GR: Acute lung injury and the acute respiratory distress syndrome: a clinical review. Lancet 2007, 369:1553-1564.

8. Pinhu L, Whitehead T, Evans T, Griffiths M: Ventilator-associated lung injury. Lancet 2003, 361:332-340.

9. Bodenstein $M$, Wang $H$, Boehme $S$, Baumgardner JE, Duenges B, Vogt A, David M, Markstaller K: Observation of ventilation-induced Spo(2) oscillations in pigs: first step to noninvasive detection of cyclic recruitment of atelectasis? Exp Lung Res 2010, 36:270-276.

10. Shi C, Boehme S, Hartmann EK, Markstaller K: Novel technologies to detect atelectotrauma in the injured lung. Exp Lung Res 2011, 37:18-25.

11. Baumgardner JE, Markstaller K, Pfeiffer B, Doebrich M, Otto CM: Effects of respiratory rate, plateau pressure, and positive end-expiratory pressure on PaO2 oscillations after saline lavage. Am J Respir Crit Care Med 2002, 166:1556-1562.

12. Gattinoni L, Caironi P, Cressoni M, Chiumello D, Ranieri VM, Quintel M, Russo S, Patroniti N, Cornejo R, Bugedo G: Lung recruitment in patients with the acute respiratory distress syndrome. N Engl J Med 2006, 354:1775-1786.

13. Briel $M$, Meade $M$, Mercat $A$, Brower RG, Talmor D, Walter SD, Slutsky AS, Pullenayegum E, Zhou Q, Cook D, Brochard L, Richard JC, Lamontagne F, Bhatnagar N, Stewart TE, Guyatt G: Higher vs lower positive endexpiratory pressure in patients with acute lung injury and acute respiratory distress syndrome: systematic review and meta-analysis. JAMA 2010, 303:865-873.

14. Hickling KG: Reinterpreting the pressure-volume curve in patients with acute respiratory distress syndrome. Curr Opin Crit Care 2002, 8:32-38.

15. Markstaller K, Eberle B, Kauczor HU, Scholz A, Bink A, Thelen M, Heinrichs W, Weiler $\mathrm{N}$ : Temporal dynamics of lung aeration determined by dynamic CT in a porcine model of ARDS. Br J Anaesth 2001, 87:459-468.

16. Neumann P, Berglund JE, Fernandez Mondejar E, Magnusson A, Hedenstierna G: Dynamics of lung collapse and recruitment during prolonged breathing in porcine lung injury. J Appl Physio/ 1998, 85:1533-1543.

17. Syring RS, Otto CM, Spivack RE, Markstaller K, Baumgardner JE: Maintenance of end-expiratory recruitment with increased respiratory rate after saline-lavage lung injury. J Appl Physiol 2007, 102:331-339.

18. Herweling A, Karmrodt J, Stepniak A, Fein A, Baumgardner JE, Eberle B, Markstaller $\mathrm{K}$ : A novel technique to follow fast $\mathrm{PaO} 2$ variations during experimental CPR. Resuscitation 2005, 65:71-78.

19. Duenges B, Vogt A, Bodenstein M, Wang H, Bohme S, Rohrig B, Baumgardner JE, Markstaller K: A comparison of micropore membrane inlet mass spectrometry-derived pulmonary shunt measurement with Riley shunt in a porcine model. Anesth Analg 2009, 109:1831-1835.

20. Evans JW, Wagner PD: Limits on $\mathrm{VA} / \mathrm{Q}$ distributions from analysis of experimental inert gas elimination. J Appl Physiol 1977, 42:889-898.

21. Folgering $H$, Smolders FD, Kreuzer F: Respiratory oscillations of the arterial $\mathrm{PO} 2$ and their effects on the ventilatory controlling system in the cat. Pflugers Arch 1978, 375:1-7.

22. Pfeiffer B, Syring RS, Markstaller K, Otto CM, Baumgardner JE: The implications of arterial Po2 oscillations for conventional arterial blood gas analysis. Anesth Analg 2006, 102:1758-1764.

23. Williams EM, Viale JP, Hamilton RM, McPeak H, Sutton L, Hahn CE: Withinbreath arterial PO2 oscillations in an experimental model of acute respiratory distress syndrome. $\mathrm{Br} J$ Anaesth 2000, 85:456-459.

24. Caironi P, Carlesso E, Gattinoni L: Radiological imaging in acute lung injury and acute respiratory distress syndrome. Semin Respir Crit Care Med 2006, 27:404-415.

25. Grasso S, Stripoli T, Sacchi M, Trerotoli P, Staffieri F, Franchini D, De Monte V, Valentini V, Pugliese P, Crovace A, Driessen B, Fiore T: Inhomogeneity of lung parenchyma during the open lung strategy: a computed tomography scan study. Am J Respir Crit Care Med 2009, 180:415-423.

26. Caironi $\mathrm{P}$, Gattinoni L: How to monitor lung recruitment in patients with acute lung injury. Curr Opin Crit Care 2007, 13:338-343. 
27. Klein $\mathrm{KU}$, Boehme $\mathrm{S}$, Hartmann EK, Duenges $\mathrm{B}$, Markstaller $\mathrm{K}: \mathrm{PaO}_{2}{ }^{-}$ oscillations caused by cyclic recruitment can be detected in the microcirculation. 2010 Annual Meeting of the American Society of Anesthesiologists San Diego, CA, USA; 2010, A1511.

28. Orakcioglu B, Sakowitz OW, Neumann JO, Kentar MM, Unterberg A, Kiening KL: Evaluation of a novel brain tissue oxygenation probe in an experimental swine model. Neurosurgery 2010, 67:1716-1722, discussion 1722-1713.

29. Wang HM, Bodenstein M, Markstaller K: Overview of the pathology of three widely used animal models of acute lung injury. Eur Surg Res 2008, 40:305-316.

30. Otto CM, Markstaller K, Kajikawa O, Karmrodt J, Syring RS, Pfeiffer B, Good VP, Frevert CW, Baumgardner JE: Spatial and temporal heterogeneity of ventilator-associated lung injury after surfactant depletion. J Appl Physiol 2008, 104:1485-1494.

31. Sinclair SE, Chi E, Lin Hl, Altemeier WA: Positive end-expiratory pressure alters the severity and spatial heterogeneity of ventilator-induced lung injury: an argument for cyclical airway collapse. J Crit Care 2009, 24:206-211.

32. Baumgardner JE, Choi IC, Vonk-Noordegraaf A, Frasch HF, Neufeld GR, Marshall BE: Sequential V(A)/Q distributions in the normal rabbit by micropore membrane inlet mass spectrometry. J Appl Physiol 2000, 89:1699-1708

33. Dunges B, Karmrodt J, Baumgardner JE, Markstaller K: Ventilation-perfusion distributions in the lungs. A novel technique for rapid measurement. Anaesthesist 2007, 56:612-616.

34. Klein KU, Boehme S, Hartmann EK, Szczyrba M, David M, Markstaller K, Engelhard $\mathrm{K}$ : A novel technique for monitoring of fast variations in brain oxygen tension using an uncoated fluorescence quenching probe (Foxy AL-300). J Neurosurg Anesthesiol 2011, 23:341-346.

35. Meier J, Habler O: Rational use of oxygen in anesthesiology and intensive care medicine. Anaesthesist 2011, 60:292-302.

36. Albert SP, DiRocco J, Allen GB, Bates JH, Lafollette R, Kubiak BD, Fischer J, Maroney S, Nieman GF: The role of time and pressure on alveolar recruitment. J Appl Physiol 2009, 106:757-765.

37. Karmrodt J, Bletz C, Yuan S, David M, Heussel CP, Markstaller K: Quantification of atelectatic lung volumes in two different porcine models of ARDS. Br J Anaesth 2006, 97:883-895.

38. Markstaller K, Kauczor HU, Weiler N, Karmrodt J, Doebrich M, Ferrante M, Thelen M, Eberle B: Lung density distribution in dynamic CT correlates with oxygenation in ventilated pigs with lavage ARDS. Br J Anaesth 2003, 91:699-708.

doi:10.1186/cc11147

Cite this article as: Hartmann et al:: Influence of respiratory rate and end-expiratory pressure variation on cyclic alveolar recruitment in an experimental lung injury model. Critical Care 2012 16:R8.

\section{Submit your next manuscript to BioMed Central and take full advantage of:}

- Convenient online submission

- Thorough peer review

- No space constraints or color figure charges

- Immediate publication on acceptance

- Inclusion in PubMed, CAS, Scopus and Google Scholar

- Research which is freely available for redistribution

Submit your manuscript at www.biomedcentral.com/submit
C Biomed Central 